\title{
EVIDENCIAÇÃO AMBIENTAL DE EMPRESAS DE SETORES POTENCIALMENTE POLUIDORES LISTADAS NO INDICE DE SUSTENTABILIDADE EMPRESARIAL (ISE)
}

\author{
Araceli Farias de Oliveira \\ Mestranda em Ciências Contábeis da Universidade Regional de Blumenau - FURB \\ Coordenadora do curso de Ciências Contábeis da Universidade do Sul de Santa Catarina - UNISUL \\ aracelio@al.furb.br \\ Débora Gomes Machado \\ Doutoranda em Ciências Contábeis da Universidade Regional de Blumenau - FURB \\ debora_furg@yahoo.com.br \\ Ilse Maria Beuren \\ Doutora em Controladoria e Contabilidade pela Universidade de São Paulo - USP \\ Professora do Programa de Pós-Graduação em Ciências Contábeis da Universidade Regional de Blumenau - FURB \\ ilse@furb.br
}

\section{RESUMO}

Este estudo objetiva identificar o nível de evidenciação de caráter ambiental divulgado, voluntariamente, pelas empresas potencialmente poluidoras listadas no Índice de Sustentabilidade Empresarial (ISE). Foi realizada pesquisa descritiva, com abordagem quantitativa, aplicando-se a técnica de análise de conteúdo nos relatórios da administração do período de 2008 a 2009 de empresas dos setores de alto impacto ambiental, de acordo com a Lei $\mathrm{n}^{\circ} 10.165 / 2000$, listadas na BM\&FBOVESPA com o Índice de Sustentabilidade Empresarial. Para a coleta dos dados, utilizou-se de uma métrica fundamentada no estudo de Rover, Murcia e Borba (2008), composta de oito categorias e 36 subcategorias ambientais. Aplicou-se o teste $t$ de Student e Análise das Componentes Principais. Os resultados mostram que a evidenciação ocorre na categoria de 'Políticas Ambientais', e no ranking de evidenciação entre as empresas a Suzano Papel se destacou. Conclui-se que, devido ao fato de a evidenciação ambiental no Brasil não ter caráter coercitivo, as empresas não atendem ao princípio da divulgação plena (full disclosure). Ainda que as empresas pesquisadas tenham sido outras e que tenha sido aplicado um corte longitudinal na coleta dos dados, os níveis de evidenciação nas categorias consideradas são semelhantes aos identificados no estudo de Rover, Murcia e Borba (2008).

Palavras-chave: Empresas com ISE; Evidenciação ambiental; Evidenciação voluntária.

\section{ENVIRONMENTAL DISCLOSURE OF COMPANIES IN POTENTIALLY POLLUTING SECTORS LISTED IN THE CORPORATE SUSTAINABILITY INDEX (ISE)}

\begin{abstract}
This study aims to identify the level of voluntarily disclosing environmental evidence by potentially polluting companies listed in the Corporate Sustainability Index (ISE). Descriptive research was performed with a quantitative approach as well as the application of the technique of content analysis on the administration reports 2008 to 2009 of companies in the sectors of high environmental impact according to Law n. 10.165/2000, listed in BM\&FBOVESPA with the Corporate Sustainability Index. Data collection used a metric based on Rover, Murcia and Borba's (2008) study, which consists of 8 categories and 36 environmental subcategories. The Student ' $t$ ' test and Principal Component Analysis were applied. The results show that disclosure happens in the category of 'Environmental Policies', and in the ranking of disclosure among companies, Suzano Papel stood out. It is concluded that due to the fact that environmental disclosure in Brazil does not have coercive character, the companies do not meet the principle of full disclosure. Although the companies surveyed have been others and applied in a longitudinal data collection, the levels of disclosure in the categories considered are similar to those identified in the study of Rover, Murcia and Borba (2008).
\end{abstract}

Keywords: Companies with ISE; Environmental disclosure; Voluntary disclosure.

Revista de Gestão Social e Ambiental - RGSA, São Paulo, v. 6, n. 1, p. 20-37, jan./abril 2012. 


\section{INTRODUÇÃO}

As empresas necessitam se conscientizar, cada vez mais, da responsabilidade social que lhes cabem, tendo em vista os recentes fatos econômicos, políticos, sociais e ambientais. Em especial, aqueles relacionados à globalização e, consequentemente, a conquista de novos mercados, as exigências de natureza ambiental, os cuidados e as características da mão de obra utilizada e as revindicações organizadas da sociedade (Ribeiro, 2006). O efeito estufa é um dos principais problemas ambientais da atualidade, porque afeta toda a humanidade. Neste contexto, a energia solar, que deveria ser dissipada de volta ao espaço, fica aprisionada na atmosfera em razão do aumento da concentração dos chamados gases estufa, ocasionando o fenômeno do aquecimento global.

No entanto, em razão da ausência de tecnologias adequadas que minimizem ou evitem a emissão de agentes poluentes, as empresas se vêem obrigadas a promover discussões e pesquisas para fazer frente as, pressões da sociedade e para atenuar o risco da diminuição de lucros por penalidades (Ribeiro, 2006). Entretanto, segundo Tibor e Feldman (1996), as empresas não encaram as obrigações ambientais como uma desvantagem financeira mas reconhecem nelas oportunidades competitivas tanto em relação a prevenção da poluição, quanto o uso de tecnologias limpas.

Na concepção de Ribeiro e Araújo (2009), em razão da cobrança da sociedade e da legislação ambiental e para manterem-se competitivas no mercado, as empresas precisam oferecer produtos que satisfaçam os consumidores, isto faz com que a gestão ambiental se torne essencial tanto no controle quanto no gerenciamento das empresas. Para o sistema de gestão ambiental alcançar os objetivos a que se propõe, de acordo com Seiffert (2007), ele precisa ser descentralizado e participativo, embasado em uma ótica integradora e ter um enfoque holístico ao longo do processo de análise de intervenção no meio ambiente.

O impacto das questões ambientais que vem provocando prejuízos para a humanidade, causados, especialmente, pelo uso de tecnologias de produção suja por parte da indústria, faz com que a sociedade propugne por informações ambientais na contabilidade das organizações. Também é exigido que sejam divulgadas as ações de gestão ambiental a fim de prevenir e corrigir danos e melhorar a vida das pessoas (Tinoco \& Kraemer, 2008). Verrecchia (2001) adverte que quando a divulgação não é obrigatória, os gestores verificam em quais circunstâncias devem divulgar as informações. Na Teoria da Divulgação, segundo Salotti e Yamamoto (2005), é possível verificar os incentivos que os gestores têm para divulgar suas informações e essa divulgação pode ser considerada um processo endógeno.

Para promover a evolução da consciência ambiental por parte das empresas, a BM\&FBOVESPA, com outras instituições, formou um Conselho Deliberativo, órgão responsável pelo desenvolvimento do Índice de Sustentabilidade Empresarial (ISE). A finalidade deste índice é a de refletir o retorno de uma carteira de ações de empresas que atuam como promotoras das boas práticas empresariais no Brasil, além de comprometer-se com a responsabilidade social e a sustentabilidade empresarial (BM\&FBOVESPA 2010).

A evidenciação das ações relacionadas ao compromisso com a responsabilidade social e a sustentabilidade empresarial deveria ser inerente, mas na legislação brasileira não há um instrumento que obriga as empresas a sua divulgação. Diante do exposto formulou-se a seguinte questão de pesquisa: Qual o nível de evidenciação de caráter ambiental divulgado voluntariamente pelas empresas potencialmente poluidoras? O objetivo do estudo é identificar o nível de evidenciação de caráter ambiental divulgado voluntariamente pelas empresas potencialmente poluidoras listadas no Índice de Sustentabilidade Empresarial (ISE).

A evidenciação ambiental, segundo Murcia et al. (2008), é um problema real das organizações e pouco abordado no âmbito acadêmico brasileiro. Considerando-se a crescente preocupação da sociedade com o meio ambiente, justificam-se mais pesquisas nessa área. Outro

Revista de Gestão Social e Ambiental - RGSA, São Paulo, v. 6, n. 1, p. 20-37, jan./abril 2012. 
ponto abordado pelos autores é a falta de padronização da evidenciação, bem como a ausência de auditoria das informações divulgadas. Em âmbito internacional, identificaram pesquisas que abordam a problemática deste estudo.

Brammer and Pavelin (2006) analisaram 450 empresas do Reino Unido com o objetivo de distinguir a qualidade da evidenciação voluntária. Os resultados apontaram que a associação da qualidade divulgação está relacionada com as grandes empresas e com os setores diretamente ligados ao meio ambiente.

Ismail and Ibrahim (2009) advertem que muita atenção tem sido dedicada por pesquisadores ao estudo e a divulgação do ambiente social de empresas. Porém, os estudos são conduzidos, na sua maioria, em países desenvolvidos e poucos em países em desenvolvimento. Os autores desenvolveram sua pesquisa na Jordânia e os resultados indicaram que $85 \%$ das empresas, de alguma forma, divulgavam as informações ambientais e sociais, embora a ambiental tenha apresentado menor divulgação entre elas.

Um estudo realizado por Damak-Ayadi' (2010) nas empresas cotadas na França, depois do advento da lei sobre as novas regras econômicas, demonstrou que a maioria das divulgações ambientais é de natureza qualitativa e que algumas informações obrigatórias foram negligenciadas por essas empresas.

Denota-se que a evidenciação, seja coerciva ou voluntária, é um problema não só no Brasil, mas em vários países. Assim, este estudo justifica-se, sob o ponto de vista teórico, por dar continuidade aos estudos internacionais e brasileiros na área ambiental. Também pretende contribuir com as empresas ao destacar a importância social que a divulgação proporciona, além de propiciar um retorno maior aos investimentos dos stakeholders.

\section{EVIDENCIAÇÃO AMBIENTAL}

De acordo com Ribeiro (2006), mesmo que a empresa esteja executando medidas voltadas à qualidade ambiental, aos olhos da sociedade, carente dessas medidas, não basta a empresa executálas; é preciso que sejam divulgadas, para que suas ações sejam refletidas e para que a sociedade assuma seu papel fiscalizador de conservação e proteção. A informação relativa à qualidade ambiental pode ao mesmo tempo beneficiar ou prejudicar a imagem da empresa, dependendo das suas ações. Ao captar recursos do meio ambiente, sejam estes renováveis ou não, a organização utiliza-se do patrimônio da humanidade.

Evidenciar informações voluntárias sobre o relacionamento da empresa com o meio social e ambiental nos relatórios da administração pode ser uma atitude atrelada à necessidade das entidades buscarem a legitimação no ambiente que passam a fazer parte, ou então, para manter sua legitimidade organizacional já reconhecida pela sociedade (Beuren, \& Boff, 2011). Por outro lado, sua legitimidade pode estar comprometida pela ocorrência de eventuais situações indesejadas que impactam sua estabilidade, surgindo, então, a necessidade de recuperá-la.

Lima, Castro e Echternacht (2006, p. 8) destacam que, “[...] ]seja pelo reconhecimento espontâneo do empresariado contemporâneo ou pela imposição do mercado, a empresa tem para com a sociedade uma grande responsabilidade, haja vista que ela impacta de forma significativa seu desenvolvimento". Lima e Viegas (2002, p. 47) ressaltam que "[...]não se trata da empresa ser, ou não, ecologicamente correta. A preocupação com a questão ambiental é ética e econômica. Dela depende a permanência da empresa no mercado".

Há uma tendência mundial dos investidores procurarem empresas socialmente responsáveis, sustentáveis e rentáveis para aplicar seus recursos. No Brasil, seguindo esta tendência, em 2005, a BM\&FBOVESPA, em conjunto com várias instituições, decidiu criar um índice de ações que fosse um referencial para os investimentos socialmente responsáveis: o Índice de Sustentabilidade Empresarial (ISE). Anteriormente a esta iniciativa, em 27 de dezembro de 2000 foi promulgada a

Revista de Gestão Social e Ambiental - RGSA, São Paulo, v. 6, n. 1, p. 20-37, jan./abril 2012. 
Lei ${ }^{\circ} 10.165 / 2000$, que dispõe sobre a Política Nacional do Meio Ambiente (PNMA), e no Anexo VIII classifica as atividades econômicas em baixo, médio e alto impacto ambiental.

$\mathrm{O}$ interesse dos stakeholders na evidenciação, e a evolução da consciência ambiental nas empresas e na sociedade têm despertado os pesquisadores. Nos últimos anos, algumas pesquisas no meio acadêmico foram desenvolvidas, tendo como objeto de estudo a evidenciação de informações ambientais. Para Tinoco e Kraemer (2008, p. 28), “[...]com o advento das informações de caráter social, que passaram a ser veiculadas com as peças contábeis das empresas, estava aberto o caminho para um passo adiante na Contabilidade, como ciência de reportar informação, para os mais diferenciados usuários".

\section{PESQUISAS SOBRE DIVULGAÇÃO DE INFORMAÇÕES AMBIENTAIS}

Diversas pesquisas podem ser identificadas na literatura sobre evidenciação ambiental, tanto em âmbito internacional quanto nacional. Este tema é recorrente e se observa uma preocupação com a divulgação das ações de responsabilidade social e de sustentabilidade empresarial. A motivação dos estudos se fundamenta na ausência de um instrumento que determine o que e quanto a contabilidade das empresas deve divulgar, ou até mesmo o não cumprimento do mínimo previsto na legislação de órgãos reguladores da matéria.

Calixto (2006) examinou as informações ambientais divulgadas por uma amostra de 80 companhias de capital aberto estabelecidas no Brasil, de 17 setores econômicos. Analisou os relatórios contábeis disponibilizados pelas companhias nos seus sites, na Comissão de Valores Mobiliários ou na Bolsa de Valores de São Paulo (BOVESPA), relativos ao período de 1997 a 2005. Os resultados obtidos confirmaram o contínuo crescimento quantitativo de informações ambientais divulgadas nos relatórios contábeis, principalmente no relatório da administração. A análise setorial permitiu identificar profundas diferenças entre setores e entre empresas. Algumas companhias divulgaram muitas informações a cada ano e outras não divulgaram qualquer informação sobre o tema estudado no período analisado.

Clarkson et al. (2007) investigaram se há contradição entre o desempenho ambiental das empresas e o nível de divulgação ambiental, de acordo com a teoria econômica e a sociopolítica, considerando a divulgação voluntária. Neste âmbito, centraram-se na evidenciação sobre informações ambientais e no desenvolvimento de um índice de análise de conteúdo com base na sustentabilidade da Global Reporting Initiative. Este índice pretende captar melhor as divulgações relacionadas com a empresa e o seu compromisso de proteger o meio ambiente do que os índices utilizados em estudos anteriores. Tendo como base esse índice, foram analisadas 191 empresas dos setores de alto impacto dos Estados Unidos e encontraram uma associação positiva entre o desempenho ambiental e o nível de divulgação ambiental. Se, por um lado, o resultado foi condizente com as previsões da teoria da divulgação econômica, mostrou-se incompatível com as previsões da teoria sociopolítica.

Lindstaedt e Ott (2007) investigaram aspectos convergentes e divergentes entre as normas e recomendações de evidenciação de informações de natureza ambiental emitidas em âmbito norteamericano e brasileiro, em relação ao modelo de evidenciação ambiental proposto internacionalmente pelo ISAR/UNCTAD. Os resultados indicaram que as normas norte-americanas, emitidas pela SEC, FASB e AICPA, apresentaram uma exigência de evidenciação nos relatórios anuais limitada à divulgação de informações sobre fatos que possam impactar na situação econômico-financeira das companhias, tendo como foco principal a proteção do investidor. Não contemplam, todavia, informações mais abrangentes relativas à sustentabilidade ambiental empresarial, como ocorre no modelo proposto pelo ISAR/UNCTAD. No âmbito brasileiro, além de a legislação societária não determinar evidenciação ambiental nos relatórios anuais, as normas emitidas pelo CFC apresentaram um nível de detalhamento muito inferior ao recomendado pelo

Revista de Gestão Social e Ambiental - RGSA, São Paulo, v. 6, n. 1, p. 20-37, jan./abril 2012. 
ISAR/UNCTAD, sendo, por isso, necessárias amplas melhorias para que atinjam o padrão internacional.

Santos, Castro Neto e Bari (2007) pesquisaram as empresas que divulgaram informações ambientais, com o intuito de verificar como as informações foram disponibilizadas ao mercado durante os anos de 2000 a 2003. Os resultados apontaram que existem, basicamente, três grupos de empresas: a) as que não fazem qualquer referência à problemática ambiental; b) outras que mencionam a questão ambiental, sem atribuir valores em seus relatórios; e c) aquelas que evidenciam projetos ambientais em curso, discriminando valores. O estudo concluiu que a evidenciação de informações ambientais nas empresas estudadas ocorreu de forma voluntária, irregular e espontânea, prejudicando a comparação entre elas.

Rover, Murcia e Borba (2008) examinaram as informações de caráter ambiental divulgadas voluntariamente pelas empresas brasileiras. O levantamento dessas informações foi realizado a partir das Demonstrações Financeiras Padronizadas (DFPs) do exercício findo em 2006. A amostra consistiu de empresas abertas com ações listadas na Bolsa de Valores de São Paulo (Bovespa), e pertencentes a setores de alto impacto ambiental, segundo a Lei $\mathrm{n}^{\circ}$. 10.165/2000, que dispõe sobre a Política Nacional do Meio Ambiente. Os resultados evidenciaram que a categoria com maior número de sentenças ambientais é a de 'Políticas Ambientais', seguida pela de 'Informações Financeiras Ambientais'. O setor que apresenta o maior volume de evidenciação ambiental é o de 'Siderurgia e Minerais Metálicos'. A Petrobras é a empresa que divulgou a maior quantidade de sentenças relacionadas ao meio ambiente. A maioria das informações é declarativa, do tipo positiva, localizada no Relatório da Administração e não auditada. Corroborando com a Teoria da Evidenciação Voluntária e com estudos anteriores, não se esperava que as empresas divulgassem voluntariamente informações negativas a respeito de suas práticas ambientais.

Nunes et al. (2008) verificaram a relação do tamanho, setor de atividade, concentração acionária e localização com a adesão das empresas ao Índice Bovespa de Sustentabilidade Empresarial (ISE). A amostra foi constituída por 119 empresas com ações mais líquidas na Bolsa que se enquadraram ou não na carteira teórica do ISE, no ano de 2007. As variáveis independentes estudadas foram: tamanho da empresa, setor de atividade, concentração acionária e localização. Os resultados apontaram que há indícios de que o tamanho das empresas e o setor de atividade são determinantes na adesão da empresa ao ISE, e que as variáveis localização e concentração acionária, estatisticamente, não apresentaram indícios de influência na inclusão das empresas ao ISE.

Aquino (2009) objetivou identificar as práticas de divulgação ambiental de 10 empresas de mineração nas Filipinas, analisando a natureza e extensão das divulgações nos relatórios anuais do ano de 2007. Observaram que não houve uniformidade nas divulgações e que não havia normas de avaliação em vigor no que diz respeito a evidenciação ambiental. Este estudo proporcionou recomendações ao Conselho para melhorar a divulgação sobre questões ambientais e discutiu os benefícios que a adoção dessas recomendações pode oferecer às empresas analisadas.

Farias e Farias (2009) verificaram a relação entre a divulgação ambiental e o desempenho ambiental das empresas abertas brasileiras. A hipótese testada foi que o desempenho ambiental influencia na estratégia de divulgação ambiental das empresas abertas brasileiras, controladas por algumas características, como exposição a custos ambientais futuros, preocupação ambiental e tamanho. Para isso, foram analisadas 87 empresas de capital aberto, que possuíam ações negociadas na Bovespa em 2005. Foi aceita a hipótese, pois o modelo mostrou uma relação estatisticamente significante entre a divulgação ambiental e o desempenho ambiental, foi observado que em 70,67\% das variações na divulgação ambiental podem ser explicadas por aquelas ocorridas no desempenho ambiental, reforçando que as estratégias das empresas da amostra, refletidas em seu desempenho ambiental, podem explicar os níveis de sua divulgação ambiental.

A pesquisa de Rover et al. (2010) teve como objetivo identificar os fatores que determinam

Revista de Gestão Social e Ambiental - RGSA, São Paulo, v. 6, n. 1, p. 20-37, jan./abril 2012. 
a divulgação voluntária ambiental pelas empresas brasileiras potencialmente poluidoras. Para tanto, foram analisadas as Demonstrações Financeiras Padronizadas (DFPs) e os Relatórios de Sustentabilidade (RSs) do período de 2005 a 2007 das empresas abertas com ações listadas na Bolsa de Valores de São Paulo (Bovespa) e pertencentes a setores de alto impacto ambiental. Foram formuladas sete hipóteses que se referem a fatores individuais das empresas, tais como tamanho, rentabilidade, endividamento, empresa de auditoria, sustentabilidade, internacionalização e publicação do RS. Os resultados mostraram que nos três anos analisados, as 57 empresas da amostra do estudo evidenciaram um total de 6.182 sentenças ambientais, sendo $73 \%$ divulgadas nos RS e $27 \%$ nas DFPs. A análise de regressão em painel demonstrou que as variáveis tamanho da empresa, sustentabilidade, empresa de auditoria e publicação do RS são relevantes a um nível de significância de 5\% para a explicação da evidenciação voluntária de informações ambientais.

Depreende-se dos estudos apresentados que há crescente divulgação de informações ambientais por algumas empresas, enquanto outras quase não as divulgam. Por se tratar de evidenciação voluntária não há uma padronização, o que dificulta que sejam feitas análises comparativas, e também não há auditoria destas informações, que lhes pudesse conferir maior credibilidade. Portanto, não há evidenciação plena das informações, mesmo quando ela é obrigatória, como se pode verificar nas pesquisas realizadas em outros países.

\section{PROCEDIMENTOS METODOLÓGICOS}

Pesquisa descritiva foi realizada por meio de procedimentos documentais e com abordagem quantitativa. De acordo com Cervo e Bervian (1996, p. 66), "[...]a pesquisa descritiva observa, analisa e correlaciona fatos ou fenômenos sem manipulá-los". Os autores relatam ainda que a pesquisa descritiva "[...]procura descobrir, com a previsão possível, a frequência com que um fenômeno ocorre, sua relação e conexão com outros, sua natureza e características".

A estratégia de pesquisa documental, segundo Martins e Theóphilo (2009, p. 55), "[...]é característica dos estudos que utilizam documentos como fonte de dados, informações e evidência". Os relatórios da administração foram utilizados como fonte de dados para investigar o nível de evidenciação ambiental das empresas nos exercícios de 2008 e 2009, dando sequência ao estudo de Rover et al. (2010), que analisou uma amostra de empresas pertencente a setores potencialmente poluidores no período de 2005 a 2007.

Quanto à abordagem, a pesquisa é de natureza quantitativa. Conforme Richardson (1999), a pesquisa quantitativa caracteriza-se pelo emprego de quantificação tanto nas modalidades de coleta de informações, quanto no tratamento delas por meio de técnicas estatísticas, desde as mais simples, como percentual, até as mais complexas.

A população da pesquisa compreendeu empresas listadas na BM\&FBovespa que compuseram o Índice de Sustentabilidade Empresarial (ISE) da BM\&FBovespa em 2009. Segundo a BM\&FBovespa (2010), o ISE reflete o retorno de uma carteira de ações de empresas que atuam como promotoras das boas práticas empresariais no meio brasileiro e que se comprometem com a responsabilidade social e a sustentabilidade empresarial.

A amostra foi intencional e não-probabilista, abrangendo apenas as empresas dos setores potencialmente de alto impacto ambiental, de acordo com o Anexo VIII da Lei $\mathrm{n}^{\circ}$ 10.165/2000. Esta Lei refere-se à Política Nacional do Meio Ambiente (PNMA) e classifica as atividades econômicas em baixo, médio e alto impacto ambiental. Na categoria de alto impacto têm-se os setores de extração e tratamento de minerais; metalúrgico; químico; papel e celulose; indústria de couros e peles; transporte, terminais, depósitos e comércio (de combustíveis, derivados de petróleo e produtos químicos).

Considerando-se as empresas participantes do ISE e, simultaneamente, pertencentes aos setores potencialmente de alto impacto ambiental, de acordo com o Anexo VIII da Lei $\mathrm{n}^{\circ}$ 10.165/2000, foi identificado um total de seis empresas, como mostra a Figura 1.

Revista de Gestão Social e Ambiental - RGSA, São Paulo, v. 6, n. 1, p. 20-37, jan./abril 2012. 


\begin{tabular}{|l|l|}
\hline Empresas & Setor \\
\hline Brasken S.A & Petroquímica \\
\hline Fíbria Celulose S.A & Papel e Celulose \\
\hline Gerdau S.A & Metalúrgica e Siderúrgica \\
\hline Natura Cosméticos S.A & Cosméticos \\
\hline Susano Papel e Celulose S.A & Papel e Celulose \\
\hline Usinas Sid de Minas Gerais S.A & Metalúrgica \\
\hline
\end{tabular}

Quadro 1: Amostra da pesquisa.

Fonte: BM\&FBovespa (2010).

A escolha dos setores potencialmente poluidores justifica-se devido aos resultados de estudos anteriores. Clarkson et al. (2007), em uma amostra de 191 empresas pertencentes aos setores poluentes encontraram uma associação positiva entre o desempenho ambiental e o nível discricionário de divulgações ambientais.

Para o levantamento dos dados, a pesquisa baseou-se na métrica do estudo precursor de Rover, Murcia e Borba (2008), que se compõe de 8 categorias e 36 subcategorias ambientais, apresentadas no Quadro 2.

\begin{tabular}{|c|c|}
\hline Categorias & Subcategorias \\
\hline \multirow[b]{4}{*}{ Políticas Ambientais } & Declaração das políticas/práticas/ações atuais e futuras \\
\hline & Estabelecimento de metas e objetivos ambientais \\
\hline & Parcerias ambientais \\
\hline & Prêmios e participações em índices ambientais \\
\hline \multirow{3}{*}{$\begin{array}{l}\text { Sistema de } \\
\text { Gerenciamento } \\
\text { Ambiental }\end{array}$} & ISO 14.000 \\
\hline & Auditoria ambiental \\
\hline & Gestão ambiental \\
\hline \multirow{8}{*}{$\begin{array}{l}\text { Impactos dos Produtos e } \\
\text { Processos no Meio } \\
\text { Ambiente }\end{array}$} & Desperdícios/Resíduos \\
\hline & Processo de acondicionamento (embalagem) \\
\hline & Reciclagem \\
\hline & Impacto na área de terra utilizada \\
\hline & Odor \\
\hline & Uso eficiente/Reutilização da água/Tratamento de efluentes \\
\hline & Vazamentos e derramamentos \\
\hline & Reparos aos danos ambientais \\
\hline \multirow[b]{4}{*}{ Energia } & Conservação e/ou utilização mais eficiente nas operações \\
\hline & Utilização de materiais desperdiçados na produção de energia \\
\hline & Discussão sobre a preocupação com a possível falta de energia \\
\hline & Desenvolvimento/Exploração de novas fontes de energia \\
\hline \multirow{6}{*}{$\begin{array}{l}\text { Informações } \\
\text { Financeiras Ambientais }\end{array}$} & Investimentos ambientais \\
\hline & Custos/Despesas ambientais \\
\hline & Passivos ambientais \\
\hline & Práticas contábeis ambientais \\
\hline & Seguro ambiental \\
\hline & Ativos ambientais tangíveis e intangíveis \\
\hline \multirow{2}{*}{$\begin{array}{l}\text { Educação e Pesquisa } \\
\text { Ambiental }\end{array}$} & Educação ambiental (internamente e/ou comunidade) \\
\hline & Pesquisas relacionadas ao meio ambiente \\
\hline \multirow{3}{*}{$\begin{array}{l}\text { Mercado de Crédito de } \\
\text { Carbono }\end{array}$} & Projetos de Mecanismos de Desenvolvimento Limpo (MDL) \\
\hline & Créditos de Carbono \\
\hline & Gases do Efeito Estufa (GEE)/Emissões atmosféricas \\
\hline Outras Informações & Menção sobre sustentabilidade/Desenvolvimento Sustentável \\
\hline
\end{tabular}

Revista de Gestão Social e Ambiental - RGSA, São Paulo, v. 6, n. 1, p. 20-37, jan./abril 2012. 
Evidenciação ambiental de empresas de setores potencialmente poluidores listadas no índice de sustentabilidade empresarial (ISE)

\begin{tabular}{|l|l|}
\hline \multirow{4}{*}{ Ambientais } & Gerenciamento de florestas/Reflorestamento \\
\cline { 2 - 2 } & Conservação da biodiversidade \\
\hline & Paisagismo e jardinagem (landscaping) \\
\cline { 2 - 2 } & Relacionamento com stakeholder \\
\hline
\end{tabular}

Quadro 2: Métrica para avaliação da evidenciação voluntária.

Fonte: Rover, Murcia e Borba (2008).

Realizou-se análise de conteúdo dos relatórios da administração do período de 2008 a 2009 da amostra de empresas. Conforme Bardin (1994, p. 31), esta representa "um conjunto de técnicas de análise das comunicações". Ainda de acordo com Bardin (1994, p. 34), esta técnica pode se valer da descrição analítica que "funciona segundo procedimentos sistemáticos e objetivos de descrição do conteúdo das mensagens".

Neste estudo não se teve a pretensão de identificar a qualidade da informação de caráter ambiental divulgada e sim o nível de evidenciação das informações. Para quantificar as categorias de evidenciação voluntária utilizou-se a análise dicotômica, sendo que o valor 1 (um) foi atribuído para as empresas que evidenciaram e 0 (zero) para as que não evidenciaram cada uma das variáveis. De acordo com Murcia (2009), a métrica utilizada possui caráter quantitativo por avaliar apenas a existência ou não de determinada informação.

Para identificar o nível de evidenciação voluntária dividiu-se o número de categorias evidenciadas pela empresa pelo total das subcategorias. Com esse critério foi estabelecido um nível de evidenciação para cada empresa no ano de 2008 e 2009. Após, optou-se por um comparativo temporal entre as médias alcançadas, realizado por meio da distribuição t de Student. Conforme Fávero et al. (2009), esta técnica é utilizada para testes de hipóteses relativos à média. Estabeleceuse a significância de 5\% para os testes estatísticos nestas análises e o intervalo de confiança de $95 \%$. Foram testadas as hipóteses:

$\mathrm{H}_{0}$ : o nível de evidenciação voluntária se igualou nos anos de 2008 e 2009; e

$\mathrm{H}_{1}$ : o nível de evidenciação voluntária não se igualou nos anos de 2008 e 2009.

De forma complementar, utilizou-se a Análise das Componentes Principais (ACP), para identificação das categorias ambientais que foram mais evidenciadas. A ACP "é uma forma de transformar as variáveis originais em componentes principais, ou seja, é uma técnica de transformação de variáveis, em que por ocasião do resultado da pesquisa, é investigado se todas as variáveis contribuíram para explicar a variabilidade total dos dados" (Morozini, Olinquevitch, \& Hein, 2006, p. 91).

\section{DESCRIÇÃO E ANÁLISE DOS RESULTADOS}

Nesta seção, inicialmente procedeu-se à quantificação das categorias de evidenciação voluntária a partir da análise de conteúdo dos relatórios da administração. Na seqüência, apresentase um comparativo temporal entre as médias alcançadas, realizado por meio da distribuição $t$ de Student. Por último, aplica-se a técnica de Análise das Componentes Principais (ACP), para identificação das categorias ambientais que foram mais evidenciadas.

\subsection{Evidenciação voluntária de acordo com as categorias ambientais}

Para análise da evidenciação e objetivando a otimização de espaço nas Tabelas 1, 2 e 3, foram elaboradas 8 categorias ambientais, sendo: A) Políticas Ambientais; B) Sistema de Gerenciamento Ambiental; C) Impactos dos Produtos e Processos no Meio Ambiente; D) Energia; E) Informações Financeiras Ambientais; F) Educação e Pesquisa Ambiental; G) Mercado de Crédito de Carbono; H) Outras Informações Ambientais. A Tabela 1 apresenta os resultados de 2008.

Revista de Gestão Social e Ambiental - RGSA, São Paulo, v. 6, n. 1, p. 20-37, jan./abril 2012. 
Tabela 1: Evidenciação voluntária 2008.

\begin{tabular}{|l|l|l|l|l|l|l|l|l|l|l|}
\hline Empresa & A & B & C & D & E & F & G & H & Total & Média \\
\hline BRASKEN & 4 & 2 & 1 & 0 & 1 & 1 & 1 & 4 & 14 & 37,8 \\
\hline FÍBRIA & 3 & 0 & 1 & 1 & 1 & 1 & 0 & 4 & 11 & 29,7 \\
\hline GERDAU & 1 & 0 & 0 & 0 & 0 & 0 & 0 & 0 & 1 & 2,7 \\
\hline NATURA & 4 & 2 & 3 & 0 & 1 & 0 & 1 & 3 & 14 & 37,8 \\
\hline SUZANO PAPEL & 4 & 3 & 5 & 1 & 1 & 2 & 3 & 4 & 23 & 62,2 \\
\hline USIMINAS & 4 & 2 & 0 & 3 & 4 & 2 & 0 & 4 & 19 & 51,4 \\
\hline Total & 20 & 9 & 10 & 5 & 8 & 6 & 5 & 19 & 82 & 36,9 \\
\hline Média & 83,3 & 50,0 & 18,5 & 20,8 & 22,2 & 50,0 & 20,8 & 63,3 & 36,9 & \\
\hline
\end{tabular}

Fonte: dados da pesquisa.

Conforme a Tabela 1, as Políticas Ambientais, categoria A, foram as mais evidenciadas. As empresas Braskem, Natura, Suzano Papel e Usiminas divulgaram informações nas quatro subcategorias que compõem a categoria A. A Gerdau foi a que menos evidenciou nessa categoria. Este resultado corrobora com o estudo de Rover, Murcia e Borba (2008) efetuado em uma amostra diferente, na qual a categoria com maior número de sentenças ambientais foi a de Políticas Ambientais.

As informações sobre Impactos dos Produtos e Processos no Meio Ambiente, categoria C, foram menos evidenciadas pelas empresas em estudo, tanto que nenhuma delas atingiu 100\% do nível de evidenciação. Nesta categoria, as informações sobre Vazamentos e Derramamentos e Reparos aos Danos Ambientais não foram mencionadas.

Chama-se a atenção para a divulgação de informações sobre Energia, categoria D, sendo a subcategoria com maior destaque a Conservação e/ou Utilização mais Eficiente das Operações. A Suzano Papel (2008) foi a que mais se destacou, por ser a única empresa que envidenciou o desenvolvimento de novas fontes de energia, como segue:

nossas unidades industriais de papel e celulose produzem uma parcela significativa da energia que consomem. Essa energia é gerada por meio de fontes renováveis, como o licor negro (subproduto gerado no processo de cozimento da madeira para extração da celulose) e a biomassa (cascas e cavacos de madeira), e também por meio de fontes não-renováveis, como gás natural e óleo combustível.

A categoria G, Mercado de Crédito de Carbono, encontra-se em estágio embrionário nas empresas pesquisadas. Apenas a Suzano Papel (2008) evidenciou no Relatório da Administração três das quatro subcategorias, destacando-se as seguintes evidenciações:

integramos diversas iniciativas nacionais e internacionais no âmbito de Mudanças Climáticas. Participamos do Chicago Climate Exchange (CCX), maior bolsa de créditos de carbono provenientes de florestas plantadas onde, em 2008 negociamos créditos de carbono equivalentes a 15 mil toneladas de carbono equivalente. Também participamos do WBCSD (World Business Council for Sustainable Development), do GHG Protocol Brasil, e anualmente do CDP (Carbon Disclosure Project). Trabalhamos em 2008 para a elaboração de um projeto de seqüestro de carbono - por meio da redução das emissões das nossas unidades fabris e da revegetação de áreas degradadas com a plantação de espécies nativas - no âmbito do Mecanismo de Desenvolvimento Limpo (MDL).

Nenhuma empresa evidenciou o certificado de emissões reduzidas. A variável Estufa (GEE)

Revista de Gestão Social e Ambiental - RGSA, São Paulo, v. 6, n. 1, p. 20-37, jan./abril 2012. 
ou emissões foi destacada por três empresas: Braskem, Natura e Suzano Papel. No Relatório da Administração da Natura (2008) consta que:

em 2008, demos importantes passos no aprimoramento de nosso desempenho ambiental. Para atingir aos objetivos do projeto Carbono Neutro - compensar as emissões de Gases de Efeito Estufa (GEEs) geradas por toda nossa cadeia produtiva - lançamos editais públicos e selecionamos cinco projetos em diferentes regiões do Brasil, como o que promove o uso de biomassa renovável na indústria cerâmica, em São Miguel do Guamá (PA), Cristolândia e Paraíso do Tocantins (TO). Essas iniciativas compensaram nossas emissões de 2007.

Assim como no ano de 2008, procedeu-se a análise das categorias e subcategorias de divulgação de informações ambientais nos relatórios da administração de 2009. Verifica-se na Tabela 2, que a categoria Políticas Ambientais, categoria A, se destaca com um índice de 79,20\%. As empresas Braskem, Natura e Suzano Papel se destacaram, evidenciando as quatro subcategorias. Porém, os resultados indicam concordância com o estudo realizado por Damak-Ayadi' (2010), que evidenciou que a maioria das divulgações ambientais são qualitativas.

Tabela 2: Evidenciação voluntária 2009.

\begin{tabular}{|l|l|l|l|l|l|l|l|l|l|l|}
\hline Empresa & A & B & C & D & E & F & G & H & Total & Média \\
\hline BRASKEN & 4 & 2 & 3 & 0 & 1 & 1 & 1 & 4 & 16 & 43,2 \\
\hline FÍBRIA & 3 & 1 & 1 & 1 & 1 & 1 & 0 & 4 & 12 & 32,4 \\
\hline GERDAU & 1 & 0 & 0 & 0 & 0 & 0 & 0 & 0 & 1 & 2,7 \\
\hline NATURA & 4 & 2 & 3 & 0 & 1 & 1 & 1 & 3 & 15 & 40,5 \\
\hline $\begin{array}{l}\text { SUZANO } \\
\text { PAPEL }\end{array}$ & 4 & 3 & 2 & 1 & 1 & 1 & 2 & 4 & 18 & 48,6 \\
\hline USIMINAS & 3 & 3 & 3 & 2 & 4 & 0 & 0 & 2 & 17 & 45,9 \\
\hline Total & 19 & 11 & 12 & 4 & 8 & 4 & 4 & 17 & 79 & 35,6 \\
\hline Média & 79,2 & 61,1 & 22,2 & 16,7 & 22,2 & 33,3 & 16,7 & 56,7 & 35,6 & \\
\hline
\end{tabular}

Fonte: dados da pesquisa.

Todas as empresas divulgaram Prêmios e Participações em Índices Ambientais. Não poderia ser diferente, já que todas as empresas estão inclusas no Índice se Sustentabilidade empresarial na carteira de 2009. Nesta subcategoria a Suzano Papel (2009) evidenciou que:

uma importante conquista em 2009 foi o Pulp and Paper International (PPI) Award na categoria Melhor Estratégia Empresarial da indústria mundial. Este prêmio é concedido pela RISI - empresa provedora mundial de informações para a indústria de base florestal e foi entregue em Munique no dia 28 de outubro. Trata-se do reconhecimento internacional da qualidade de nosso Processo de Planejamento Estratégico, que inclui a Criação de Valor nas atividades florestais, no Crescimento Orgânico Acelerado na produção de celulose de eucalipto, Excelência nas Operações de produção e comercialização de papel e Sustentabilidade em tudo que fazemos.

A categoria B, Sistema de Gerenciamento Ambiental, apresentou um índice de 61,1\%. Nesta categoria identificaram-se sentenças sobre Auditora Ambiental e ISO 14.000, nas empresas Braskem, Natura, Suzano Papel e Usiminas, como se pode observar:

As duas usinas da Companhia renovaram em 2009 as licenças de operação e as classificações na norma ISO 14001, demonstrando a qualidade da performance ambiental da Usiminas. Além disso, a usina de Cubatão

Revista de Gestão Social e Ambiental - RGSA, São Paulo, v. 6, n. 1, p. 20-37, jan./abril 2012. 
recebeu a certificação da Diretiva Europeia Restriction of Hazardous Substances (RoHS) e End-of-life Vehicle Act (ELV), que verifica as iniciativas das empresas quanto à proteção do solo, da água e do ar contra a poluição. A usina de Ipatinga havia recebido a certificação em 2007, passou por um processo de auditoria em 2009 e foi novamente aprovada (Usiminas, 2009).

De acordo com Lindstaedt e Ott (2007), "no âmbito brasileiro, além da legislação societária não determinar evidenciação ambiental nos relatórios anuais, as normas emitidas pelo CFC apresentam um nível de detalhamento muito inferior ao recomendado pelo ISAR/UNCTAD". Acredita-se que por haver carência na legislação sobre a evidenciação são dificultados os trabalhos dos auditores independentes. Foi evidenciada existência de ISO 14.000 nas empresas Suzano Papel e Usiminas.

As categorias D, Energia, e G, Mercado de Crédito de Carbono, obtiveram nível menor de evidenciação. A Suzano Papel se sobressaiu nas duas categorias com um nível de evidenciação de $50 \%$ das subcategorias. Também foi divulgado no Relatório da Administração da Brasken (2009) sobre emissões:

em 2009, a Braskem finalizou o inventário de emissões em todas as suas plantas, com base no ano de 2008. As emissões diretas do ano de 2008 foram de 7.406.854,12 tCO2 e as emissões indiretas foram de 186.449,36 toneladas de $\mathrm{CO} 2$. As emissões diretas, que representam $97,5 \%$ do total de $\mathrm{CO} 2$ emitido pela Braskem, caíram, em 2008, 9\% em relação a 2007.

Percebe-se que algumas empresas evidenciaram mais informações nos dois anos seguintes, enquanto outras pouco divulgaram. Isso vem ao encontro da pesquisa de Calixto (2006), na qual identificou que algumas empresas divulgaram muitas informações a cada ano e outras não divulgaram qualquer informação sobre o tema no período analisado.

\subsection{Comparativo temporal entre as médias alcançadas}

Como as empresas em análise não atingiram a divulgação plena (full disclosure), na Tabela 3 apresenta-se um comparativo entre os dois anos em análise.

Tabela 3: Comparativo entre a evidenciação voluntária de 2008 e 2009.

\begin{tabular}{|l|l|l|l|l|l|l|l|l|l|}
\hline Ano & A & B & C & D & E & F & G & H & Total \\
\hline Totais 2008 & 20 & 9 & 10 & 5 & 8 & 6 & 5 & 19 & 82 \\
\hline Totais 2009 & 19 & 11 & 12 & 4 & 8 & 4 & 4 & 17 & 79 \\
\hline Média 2008 & 83,3 & 50 & 18,5 & 20,8 & 22,2 & 50 & 20,8 & 63,3 & 36,9 \\
\hline Média 2009 & 79,2 & 61,1 & 22,2 & 16,7 & 22,2 & 33,3 & 16,7 & 56,7 & 35,6 \\
\hline
\end{tabular}

Fonte: dados da pesquisa.

O comparativo entre os anos, apresentado na Tabela 3, mostra que as categorias Políticas Ambientais (A), Energia (D), Educação e Pesquisa Ambiental (F), Mercado de Crédito de Carbono (G) e Outras Informações Ambientais $(H)$, sofreram uma redução no nível de divulgação do ano de 2008 para 2009. Por outro lado, houve aumento na categoria Sistema de Gerenciamento Ambiental (B). Por sua vez, Impactos de Produtos e Processos no Meio Ambiente (C) e Informações Financeiras Ambientais (E) permaneceram inalteradas.

Algumas informações, como Parcerias Ambientais, foram mencionadas pela Usiminas (2008) somente no primeiro ano. A Fíbria (2009) destacou a categoria Gestão Ambiental somente no segundo ano. A categoria de Auditoria Ambiental, somente no segundo ano, foi mencionada pela empresa Usiminas (2009): “[...]a usina de Ipatinga havia recebido a certificação ambiental em 2007,

Revista de Gestão Social e Ambiental - RGSA, São Paulo, v. 6, n. 1, p. 20-37, jan./abril 2012. 
passou por um processo de auditoria em 2009 e foi novamente aprovada".

Os resultados coadunam com os de Santos, Castro Neto e Bari (2007), que observaram que a evidenciação de informações ambientais nas empresas estudadas ocorreu de forma voluntária e irregular, prejudicando a comparação entre elas. Os autores encontraram empresas que: a) não evidenciam informações ambientais; b) mencionam a questão ambiental, sem atribuir valores; e c) evidenciam projetos ambientais em curso, discriminando valores.

De forma geral, observa-se um pequeno decréscimo no nível de evidenciação voluntária, que em 2008 foi de 36,90\% e em 2009, 35,60\%. Testaram-se as hipóteses por meio do teste de student de médias, refutando-se a $\mathrm{H}_{1}$, de que o nível de evidenciação voluntária não é igual no ano de 2008 e 2009. A diferença estatística foi de 2,62\%, portanto insignificante. O t calculado, de 0,920452.

\subsection{Análise das componentes principais (ACP)}

Na análise dos dados foi também utilizada a técnica da Análise das Componentes Principais. Inicialmente a ACP foi aplicada aos dados do ano de 2008, conforme apresentado no Apêndice A. $\mathrm{O}$ resultado da ACP mostra que apenas duas componentes obtiveram autovalores acima de 1, indicando que há duas dimensões diferentes para as categorias analisadas. A primeira categoria (Políticas Ambientais) explica 53,65\% e esta com a outra (Sistema de Gerenciamento Ambiental) explicam 85,20\% de inércia (variância) dos dados. As demais componentes ficaram próximas de zero, o que justifica a escolha de apenas duas delas.

No Apêndice B demonstra-se a análise das componentes principais do ano de 2009. A grandeza dos valores é muito próxima de zero na maioria das categorias, justificando a escolha de duas componentes principais com valores maiores que 1. A primeira componente (Políticas Ambientais) já explica 60,48\% da inércia (variância) dos dados em análise. Esta componente, acumulada com a segunda (Sistema de Gerenciamento Ambiental) explicam 87,60\% da inércia (variância) dos dados.

Apresentam-se no Apêndice C os coeficientes de correlação do ano de 2008. Na primeira componente houve agrupamento de quatro categorias pesquisadas: Políticas Ambientais, Sistema de Gerenciamento Ambiental, Educação e Pesquisa Ambiental e Outras Informações Ambientais. A segunda componente agrupou os Impactos dos Produtos e Processos no Meio Ambiente e Mercado de Crédito de Carbono.

No Apêndice D evidencia-se a análise dos coeficientes de correlação do ano de 2009.

Nas duas componentes principais verifica-se no primeiro momento o agrupamento por coeficientes de correlação das Políticas Ambientais, Sistema de Gerenciamento Ambiental e Outras Informações Ambientais. O segundo grupo foi formado por duas categorias: Informações Financeiras Ambientais e Energia.

Para uma análise conjunta da evidenciação de informações ambientais, no relatório da administração dos anos de 2008 e 2009 das empresas objeto de estudo, estabeleceu-se um ranking. Na Tabela 4 é apresentado o ranking das empresas.

Tabela 4: Ranking da evidenciação voluntária de 2008 e 2009.

\begin{tabular}{|l|l|l|l|}
\hline Empresas & Ranking 2008 & Empresas & Ranking 2009 \\
\hline SUZANO PAPEL & 19,39 & SUZANO PAPEL & 15,90 \\
\hline USIMINAS & 15,86 & USIMINAS & 15,44 \\
\hline NATURA & 11,70 & BRASKEN & 14,23 \\
\hline BRASKEN & 11,44 & NATURA & 13,36 \\
\hline FÍBRIA & 8,90 & FÍBRIA & 10,81 \\
\hline GERDAU & 0,81 & GERDAU & 0,96 \\
\hline
\end{tabular}

Fonte: dados da pesquisa.

Revista de Gestão Social e Ambiental - RGSA, São Paulo, v. 6, n. 1, p. 20-37, jan./abril 2012. 
O ranking de 2008 foi calculado por meio da fórmula: Ranking $=0,811478$ Cat $1+0,841935$ Cat2+0,897998 Cat3+0,885005 Cat4+0,933005 Cat5+0,78786 Cat6+0,925591 Cat7+0,740651 Cat8. Onde: os valores da fórmula correspondem aos coeficientes de correlação multiplicados pela quantidade evidenciada por categoria para cada uma das empresas da amostra.

O ranking de 2009 foi calculado por meio da fórmula: Ranking $=0,964982$ Cat $1+0,935946$ Cat2+0,806628 Cat3+0,821039 Cat4+0,985982 Cat5+0,906142 Cat6+0,721531 Cat7+0,866053 Cat8. Onde: Os valores da fórmula correspondem aos coeficientes de correlação multiplicados pela quantidade evidenciada por categoria para cada uma das Instituições de Ensino Superior.

Observa-se que em 2008 a empresa Suzano Papel foi a que mais evidenciou voluntariamente suas informações ambientais, seguida pela Usiminas e Natura. Em 2009, novamente a empresa Suzano Papel foi a que mais se destacou no nível de evidenciação, com 15,90, seguida pela Usiminas e pela Braskem. A Natura desceu do $3^{\circ}$ lugar em 2008 para o $4^{\circ}$ lugar em 2009. A Gerdau reagiu timidamente de 2008 para 2009, porém sua evidenciação continua muito abaixo das demais empresas pesquisadas.

A última posição ocupada pela empresa Gerdau no ranking de evidenciação de informações ambientais pode denotar uma estratégia empresarial de não reportar suas ações sociais e ambientais, como também pode representar uma política de não investir em práticas de gestão ambiental. Ambas as alternativas parecem não corresponder com a necessidade de legitimação das empresas pela sociedade, conforme descrito em Beuren e Boff (2011).

\section{CONSIDERAÇÕES FINAIS}

Este estudo objetivou identificar o nível de evidenciação de caráter ambiental divulgado voluntariamente pelas empresas potencialmente poluidoras listadas no Índice de Sustentabilidade Empresarial (ISE). No ano de 2008, obteve-se um nível de 36,9\% e no ano de 2009 de 35,6\%. No teste das médias, não houve diferença estatística entre elas. A categoria mais evidenciada nos dois anos foi a de Políticas Ambientais; e as menos divulgadas foram as categorias de Energia e Impactos dos Processos no Meio Ambiente.

No comparativo entre os exercícios analisados, verificaram-se as categorias, Políticas Ambientais, Energia, Educação e Pesquisa Ambiental, Mercado de Crédito de Carbono e Outras Informações Ambientais, com uma redução no nível de divulgação do primeiro ano para o segundo. Houve aumento na categoria Sistema de Gerenciamento Ambiental. Por sua vez, Impactos de Produtos e Processos no Meio Ambiente e Informações Financeiras Ambientais permaneceram inalterados.

A aplicação da técnica de Análise das Componentes Principais indicou a existência de duas dimensões diferentes para as categorias analisadas nos dois períodos. No ano de 2008, a primeira componente explicou 53,65\% e em 2009 explicou 60,48\% da inércia (variância) dos dados em análise. Os coeficientes de correlação do ano de 2008 agruparam quatro categorias: Políticas Ambientais, Sistema de Gerenciamento Ambiental, Educação e Pesquisa Ambiental e outras informações ambientais. No ano de 2009, houve o agrupamento por coeficientes de correlação das Políticas Ambientais, Sistema de Gerenciamento Ambiental e Outras Informações Ambientais.

No ranking da evidenciação de 2008 e 2009, a empresa Suzano Papel foi a que mais evidenciou voluntariamente suas informações referentes às questões ambientais, seguida pela Usiminas. No ano de 2009, a Natura desceu do terceiro lugar em 2008 para o quarto lugar em 2009. A Gerdau reagiu timidamente de 2008 para 2009, porém sua evidenciação continua muito abaixo do ideal. Os resultados coadunam com a Teoria da Evidenciação Voluntária (Verrecchia, 2001), que, quando a divulgação não é obrigatória, os gestores verificam em quais circunstâncias é conveniente divulgar informações.

Conclui-se que, pelo fato de não ter caráter coercitivo, a evidenciação ambiental no Brasil,

Revista de Gestão Social e Ambiental - RGSA, São Paulo, v. 6, n. 1, p. 20-37, jan./abril 2012. 
as empresas não atendem ao princípio da divulgação plena (full disclosure). Ainda que as empresas pesquisadas tenham sido outras e aplicado um corte longitudinal na coleta dos dados, os níveis de evidenciação nas categorias consideradas são semelhantes aos identificados no estudo de Rover, Murcia e Borba (2008).

Os resultados da pesquisa instigam algumas reflexões sobre a evidenciação de informações ambientais. Inicialmente, as transcrições de trechos evidenciados no relatório da administração indicam que é mais comum reportar aspectos positivos do que negativos da relação da empresa com o ambiente. Geralmente, são reportados dados qualitativos, suprimindo valores monetários, principalmente se forem de caráter negativo para a imagem da empresa. A falta de auditoria destes relatos pode prejudicar a qualidade da divulgação.

Espera-se que os resultados da pesquisa possam contribuir para subsidiar discussões de órgãos reguladores da contabilidade, especialmente os voltados à evidenciação de informações ambientais. Recomenda-se para futuros estudos investigar empresas que não estejam listadas e comparar os resultados, a fim de verificar se o conselho deliberativo do ISE consegue estimular as empresas a aumentar o nível de divulgação de suas ações de responsabilidade social e de sustentabilidade empresarial.

\section{REFERÊNCIAS}

Aquino, N.M. (2009). An evaluation of financial and non-financial environmental disclosures of ten publicly-listed minong companies in the Philippines. DLSU Business \& Economics Review, 18(2), $55-64$.

Bardin, L. (1994). Análise de conteúdo. Lisboa: Edições 70.

Beuren, I.M., \& Boff, M.L. (2011). Predominant strategies of legitimacy in environmental and social disclosures. Management Research: The Journal of the Iberoamerican Academy of Management, 9(1), 56-72.

Bolsa de Valores, Mercadorias e Futuros (BM\&FBOVESPA). Empresas listadas. Recuperado em 18 agosto, 2010, de: http://www.bmfbovespa.com.br/cias-listadas/empresaslistadas/BuscaEmpresaListada.aspx?idioma=pt-br

Brammer, S., \& Pavelin, S. (2006). Factors influencing the quality of corporate environmental disclosure. Business Strategy and the Environment, 17, 120-136.

Brasil. Lei $n^{\circ}$ 10.165, de 27 de dezembro de 2000. (2000, dezembro 27). Altera a Lei $\mathrm{n}^{\circ}$ 6.938, de 31 de agosto de 1981, que dispõe sobre a Política Nacional do Meio Ambiente, seus fins e mecanismos de formulação e aplicação, e dá outras providências. Brasília, DF, Diário Oficial da União.

Brasken (2009). Relatório da Administração. Recuperado em 18 agosto, 2010, de: http://www.bmfbovespa.com.br/dxw/AbrirDoc.asp?gstrIDTDESCRICAONUMERO=13.01\&gstrI DTQDRODESCRICAO=RELATÓRIODAADMINISTRAÇÃO\&gstrIdtQdro=dfpadmin

Calixto, L. (2006) Uma análise da evidenciação ambiental de companhias brasileiras - de 1997 a 2005. Anais do Congresso Brasileiro de Custos, Belo Horizonte, BH, Brasil, 13.

Cervo, A.L., \& Bervian, A. (1996) Metodologia científica: para uso dos estudantes universitários. (3. ed.). São Paulo: McGraw-Hill do Brasil.

Revista de Gestão Social e Ambiental - RGSA, São Paulo, v. 6, n. 1, p. 20-37, jan./abril 2012. 
Clarkson, P.M., Li, Y., Richardson, G.D., \& Vasvari, F.P. (2007). Revisiting the relation between environmental performance and environmental disclosure: an empirical analysis. Accounting, Organizations and Society, 33, 303-327.

Damak-Ayadi, S. (2010). Social and environmental reporting in the annual reports of large companies in France. Accounting and Management Information Systems, 9(1), 22-34.

Farias, K.T.R., \& Farias, M.R.S. (2009). Influência do desempenho ambiental na estratégia de divulgação ambiental das empresas abertas brasileiras. Anais do Encontro da Associação Nacional dos Programas de Pós-Graduação em Administração, São Paulo, SP, Brasil, 33.

Fávero, L.P., Belfiore, P., Silva, F.L., \& Chan, B.L. (2009). Análise de dados: modelagem multivariada para tomada de decisões. Rio de Janeiro: Elsevier.

Fibria. (2009). Relatório da Administração. Recuperado em 19 agosto, 2010, em: http:// www.bmfbovespa.com.br/dxw/FrDXW.asp?site=B\&mercado=18\&razao=FIBRIACELULOSE S.A.\&pregao $=$ FIBRIA\&ccvm $=12793 \&$ data $=31 / 12 / 2009 \&$ tipo $=2$

Ismail, K.N.I.K., \& Ibrahim, A.H. (2009). Social and environmental disclosure in the annual reports of Jordanian companies. Issues in Social and Environmental Accounting, 2(2), 198-210.

Lima, D.V., \& Viegas, W. (2002). Tratamento contábil e evidenciação das externalidades ecológicas. Revista Contabilidade \& Finanças, 30, 46-53.

Lima, F.B., Castro, R.C.S., \& Echternacht, T.H.S. (2006). Responsabilidade social empresarial no Brasil: da filantropia à estratégia corporativa. Anais do Congresso Internacional de Contabilidade e Auditoria, Coimbra, Portugal, 11.

Lindstaedt, A.R.S., \& Ott, E. (2007). Evidenciação de informações ambientais pela contabilidade: um estudo comparativo entre as normas Internacionais (ISAR/UNCTAD), Norte-Americanas e Brasileiras. Anais do Congresso Anpcont, Gramado, RS, Brasil, 1.

Martins, G.A., \& Theophilo, C.R. (2009). Metodologia da investigação científica para ciências sociais aplicadas. São Paulo: Atlas.

Morozini, J.F., Olinquevitch, J.L., \& Hein, N. (2006). Seleção de índices na analise de balanços: uma aplicação da técnica estatística 'ACP'. Revista Contabilidade \& Finanças, 41, 87-99.

Murcia, F.D-R. (2009). Fatores determinantes do disclosure voluntário de companhias abertas no Brasil. Tese de Doutorado, Universidade de São Paulo, São Paulo, SP, Brasil.

Murcia, F.D-R., Santos, A., Salotti, B.M., Nascimento, A.R. (2008). Mapeamento da pesquisa sobre disclosure ambiental no cenário internacional: uma revisão dos artigos publicados em periódicos de língua inglesa no período de 1997-2007. Anais do Congresso USP de Controladoria $e$ Contabilidade, São Paulo, SP, Brasil, 8.

Natura. (2008). Relatório da Administração. Recuperado em 18 agosto, 2010, em: http:// www.bmfbovespa.com.br/dxw/AbrirDoc.asp?gstrIDTDESCRICAONUMERO=13.01\&gstrIDTQD RODESCRICAO=RELATÓRIODA ADMINISTRAÇÃO\&gstrIdtQdro=dfpadmin 
Nunes, J.G., Teixeira, A.J.C., \& Silva, A.R.L. (2008). Resumo análise das variáveis que influenciam a adesão das empresas ao Índice Bovespa de Sustentabilidade Empresarial. Anais do Congresso USP de Controladoria e Contabilidade, São Paulo, SP, Brasil, 8.

Ribeiro, M.S. (2006). Contabilidade ambiental. São Paulo: Saraiva.

Ribeiro, R.B., \& Araújo, A.O. (2009). Impacto da não-reservação ambiental no resultado de uma indústria têxtil da região metropolitana de Natal. Anais do Congresso Anpcont, São Paulo, SP, Brasil, 3

Richardson, R.J. (1999). Pesquisa social: métodos e técnicas. (3. ed.). São Paulo: Atlas.

Rover, S., \& Murcia, F.D.-R. (2010). Influencia do disclosure voluntário econômico e socioambiental no custo de capital próprio de empresas brasileiras. Anais do Congresso Anpcont, Natal, RN, Brasil, 4.

Rover, S., Murcia, F.D.-R., \& Borba, J.A. (2008). Divulgação de informações ambientais nas demonstrações contábeis: um estudo exploratório sobre o disclosure das empresas brasileiras pertencentes a setores de alto impacto ambiental. Anais do Congresso Anpcont, Salvador, BA, Brasil, 2.

Rover, S., Tomazzia, E.C., Murcia, F.D.-R., \& Borba, J.A. (2010). Explicações para a divulgação voluntária ambiental no Brasil utilizando análise de regressão em painel. Anais do Congresso Anpcont, Natal, RN, Brasil, 4.

Santos, V.L.C., Castro Neto, J.L., \& Bari, M.L. (2207) Identificação das informações sobre o meio ambiente em empresas brasileiras. Anais do Congresso Brasileiro de Custos, João Pessoa, PB, Brasil, 14.

Seiffert, M.E.B. (2007). ISO 14001 sistemas de gestão ambiental: implantação objetiva $e$ econômica. (3 ed.). São Paulo: Altas.

Suzano Papel.(2009). Relatório da administração. Recuperado em 18 agosto, 2010,em: http:// www.bmfbovespa.com.br/dxw/AbrirDoc.asp?gstrIDTDESCRICAONUMERO=13.01\&gstrIDTQD RODESCRICAO=RELATÓRIOAADMINISTRAÇÃO\&gstrIdtQdro=dfpadmin

Tibor, T., \& Feldman, I. (1996). ISO 14000: um guia para novas normas de gestão ambiental. São Paulo: Futura.

Tinoco, J.E.P.; Kraemer, M.E.P. (2008). Contabilidade e gestão ambiental. (2. ed.). São Paulo: Atlas.

Verrecchia, R. (2001). Essays on disclosure. Journal of Accounting and Economics, 22, 97-180.

Usiminas. (2009). Relatório da Administração. Recuperado em 19 agosto, 2010, em: http://www.bmfbovespa.com.br/dxw/AbrirDoc.asp?gstrIDTDESCRICAONUMERO=13.01\&gstrI DTQDRODESCRICAO=RELATÓRIODAaDMINISTRAÇÃO\&gstrIdtQdro=dfpadmin 
Apêndice A - Análise das Componentes Principais 2008

\begin{tabular}{|c|c|c|c|c|c|c|}
\hline \multicolumn{7}{|c|}{ Análise das Componentes Principais } \\
\hline \multirow{2}{*}{ Componentes } & \multicolumn{3}{|c|}{ Auto Valor Inicial } & \multicolumn{3}{|c|}{$\begin{array}{l}\text { Somas extraídas dos } \\
\text { carregamentos quadráticos }\end{array}$} \\
\hline & Total & $\begin{array}{l}\text { \% da } \\
\text { Variância }\end{array}$ & $\begin{array}{l}\% \\
\text { Acumulado }\end{array}$ & Total & $\begin{array}{l}\text { \% da } \\
\text { Variância }\end{array}$ & $\begin{array}{l}\% \\
\text { Acumulado }\end{array}$ \\
\hline 1 & 4,292 & 53,65 & 53,65 & 4,292 & 53,650 & 53,650 \\
\hline 2 & 2,524 & 31,56 & 85,21 & 2,524 & 31,555 & 85,206 \\
\hline 3 & 0,624 & 7,80 & 93,01 & & & \\
\hline 4 & 0,393 & 4,92 & 97,93 & & & \\
\hline 5 & 0,166 & 2,07 & 100,00 & & & \\
\hline 6 & 0,000 & 0,00 & 100,00 & & & \\
\hline 7 & 0,000 & 0,00 & 100,00 & & & \\
\hline 8 & 0,000 & 0,00 & 100,00 & & & \\
\hline
\end{tabular}

Apêndice B - Análise das Componentes Principais 2009

\begin{tabular}{|c|c|c|c|c|c|c|}
\hline \multicolumn{7}{|c|}{ Análise das Componentes Principais } \\
\hline \multirow{2}{*}{ Componentes } & \multicolumn{3}{|c|}{ Auto Valor Inicial } & \multicolumn{3}{|c|}{$\begin{array}{l}\text { Somas extraídas dos } \\
\text { carregamentos quadráticos }\end{array}$} \\
\hline & Total & $\begin{array}{l}\text { \% da } \\
\text { Variância }\end{array}$ & $\begin{array}{l}\% \\
\text { Acumulado }\end{array}$ & Total & $\begin{array}{l}\text { \% da } \\
\text { Variância }\end{array}$ & $\begin{array}{l}\% \\
\text { Acumulado }\end{array}$ \\
\hline 1 & 4,838 & 60,48 & 60,48 & 4,838 & 60,478 & 60,478 \\
\hline 2 & 2,170 & 27,13 & 87,60 & 2,170 & 27,125 & 87,604 \\
\hline 3 & 0,529 & 6,61 & 94,21 & & & \\
\hline 4 & 0,424 & 5,30 & 99,51 & & & \\
\hline 5 & 0,028 & 0,35 & 99,86 & & & \\
\hline 6 & 0,011 & 0,14 & 100,00 & & & \\
\hline 7 & 0,000 & 0,00 & 100,00 & & & \\
\hline 8 & 0,000 & 0,00 & 100,00 & & & \\
\hline
\end{tabular}

Apêndice C - Análise dos Coeficientes de Correlação 2008

\begin{tabular}{|l|l|l|}
\hline Análise dos Coeficientes de Correlação & \multicolumn{2}{l|}{ Componentes } \\
\hline & $\mathbf{1}$ & $\mathbf{2}$ \\
\hline Categorias Ambientais & 0,898 & 0,068 \\
\hline Políticas Ambientais & 0,854 & 0,335 \\
Sistema de Gerenciamento Ambiental & 0,534 & 0,783 \\
Impactos dos Produtos e Processos no Meio Ambiente & 0,561 & $-0,755$ \\
Esquema Básico de Custos & 0,614 & $-0,745$ \\
Energia & 0,833 & $-0,295$ \\
Educação e Pesquisa Ambiental & 0,595 & 0,756 \\
Mercado de Crédito de Carbono & 0,854 & $-0,104$ \\
Outras Informações Ambientais & &
\end{tabular}

Apêndice D - Análise dos Coeficientes de Correlação 2009

\begin{tabular}{|l|l|l|}
\hline Análise dos Coeficientes de Correlação & \multicolumn{2}{l|}{ Componentes } \\
\hline Categorias Ambientais & $\mathbf{1}$ & $\mathbf{2}$ \\
\hline Políticas Ambientais & 0,970 & $-0,156$ \\
Sistema de Gerenciamento Ambiental & 0,927 & 0,278 \\
Impactos dos Produtos e Processos no Meio Ambiente & 0,885 & 0,152 \\
Esquema Básico de Custos & 0,445 & 0,789 \\
Energia & 0,544 & 0,831 \\
Educação e Pesquisa Ambiental & 0,715 & $-0,628$ \\
Mercado de Crédito de Carbono & 0,680 & $-0,509$ \\
Outras Informações Ambientais & 0,888 & $-0,280$ \\
\hline
\end{tabular}


Evidenciação ambiental de empresas de setores potencialmente poluidores listadas no índice de sustentabilidade empresarial (ISE)

Data do recebimento do artigo: 06/09/2010

Data do aceite de publicação: 27/09/2011 